\title{
Review on Sperata seenghala (Sykes, 1839), A Freshwater Catfish of Indian Subcontinent
}

\author{
Sandipan Gupta* \\ Central Inland Fisheries Research Institute (ICAR), Barrackpore, Kolkata-700120, India
}

\begin{abstract}
Sperata seenghala is one of the largest freshwater catfish of Indian sub-continent. This fish has good market demand as food fish due to its good taste with high nutritional value and for this reason it constitutes an important capture fishery of all the major rivers and reservoirs of India, Bangladesh and Pakistan. Earlier number of works has been carried out on its food and feeding habit, reproductive biology, morphology, fishery, captive culture etc, but no such consolidated review report is available. With this view the current review work has been carried out to sum up all available information along with gathering up the lacunae of information which will be helpful for future fishery and management of this fish species. It has been documented that comprehensive information is available on its food and feeding habit but further investigations are needed to put firm conclusion on some aspects of its reproductive biology and to gather proper knowledge on its captive culture technique.
\end{abstract}

Keywords: Food; Reproduction; Biology; Morphology; Fishery; Captive culture; Sperata seenghala

\section{Introduction}

Sperata seenghala (Sykes, 1839) is one of the largest freshwater catfish; widely distributed in rivers, reservoirs, lakes, floodplains, inundated swamp fields, ditches, canals and other freshwater areas of Afghanistan, Pakistan, India, Bangladesh, Thailand, Myanmar and Nepal [1-10], its availability in China waters has been reported by Jayaram [3]. This species can tolerate high range of temperature, salinity and variable water conditions $[8,11]$. Its adults and juveniles are bottom and marginal dwellers; fry are used to inhabit the shallow marginal area of river and marginal pits connecting the river; larvae live in the nests formed among rocks and soft muddy beds of rivers [8]. It has been considered as one of the most admired edible fishes due to its good taste and low number of intramuscular bones [10,12,13], it has high nutritional value with good protein content [14-16]; each gram of its flesh contains 200 unit of vitamin A [17]. It is a popular species of catfish to capture because it fetches a higher price than carp [7]. Recently it has also got its importance in ornamental fish market and has been reported to be exported from India as indigenous ornamental fish $[18,19]$. Earlier number of works has been carried out on different aspects of its morphology, biology, fishery and captive culture but no consolidated report is available on these. With this view, the current review work has been conducted to sum up all those previously documented information with noting down the lacunae of information which will be helpful for its future fishery and management.

\section{Morphology}

Day [1], Talwar and Jhingran [6] and Chondar [8] have earlier well documented the morphological characters of Sperata seenghala which have been compiled here:

Body devoid of scales, elongated and compressed; dorsal profile from rayed dorsal fin shallowly concave up to caudal peduncle; abdomen convex and broad. Head long, 4.1 to 4.5 in the total length. Snout broad and spatulate, upper jaw rather the longer. Mouth almost terminal, with shallow cleft reaching half the way to the orbit, and width of gape equals to $1 / 3^{\text {rd }}$ of head length. Upper surface of the head granulated in ridges, its median longitudinal groove extends up to the base of occipital process which is twice as long as wide at its base, separated from basal bone of dorsal fin by an intermediate interneural shield and from 4 times as long as broad in the young to half that width in the adult. Barbels- 4 pairs; the maxillary ones extend to the middle or just beyond the hind margin of the dorsal fin, the nasal to opposite the middle of the orbit, the external mandibular ones to the base of the pectoral fin, whilst the internal ones are one-third shorter. Teeth- Palatine teeth in an uninterrupted crescentic band. Fins- Two dorsal fins, the first with one spine and a few rays, and the second dorsal is adipose. Dorsal spine weak, rugose anteriorly, weakly serrated posteriorly, and as long as the head excluding the snout. Adipose dorsal markedly large, its basal length equals or exceeds the length of the base of the rayed dorsal, whilst the intermediate distance is of the same length. Pectoral extends rather above half way to the pelvic; its spine is stronger than that of the dorsal and half as long as the head, roughened externally, denticulated internally. Pelvic fin abdominal, originating behind last ray of dorsal and reaches $2 / 3^{\text {rd }}$ of the distance to the anal. Caudal fin deeply forked, upper lobe longer with its tip bending downwardly. Color- brownish along the back, silvery on the flanks and beneath; a round black spot is present at the posterior end of the base of the adipose dorsal fin.

In adult stage, Sperata seenghala is almost alike with Sperata aor, but it can be chiefly distinguishable from Sperata aor by few characters like chisel-shaped snout, distantly placed rayed and adipose dorsal fins and much shorter maxillary barbels not exceeding beyond the tip of the pelvic fin.

Sperata seenghala usually attains large size; Job et al. [20] have reported specimen of $122 \mathrm{~cm}$ from Mahanadi while Alikunhi [21] has documented maximum length of about $183 \mathrm{~cm}$ for this fish species.

*Corresponding author: Sandipan Gupta, Central Inland Fisheries Research Institute (ICAR), Barrackpore, Kolkata-700120, India, Tel: 9830082686; E-mail: sandipangupta2007@gmail.com

Received October 17, 2014; Accepted November 07, 2014; Published January 10, 2015

Citation: Gupta S (2015) Review on Sperata seenghala (Sykes, 1839), A Freshwater Catfish of Indian Subcontinent. J Aquac Res Development 6: 290. doi:10.4172/2155-9546.1000290

Copyright: (C) 2015 Gupta S. This is an open-access article distributed under the terms of the Creative Commons Attribution License, which permits unrestricted use, distribution, and reproduction in any medium, provided the original author and source are credited. 
Misra [22], Saigal and Motwani [2], Kolekar and Choudhury [23] and Ratanatrivong et al. [24] have documented maximum length of about $224 \mathrm{~cm}, 114.6 \mathrm{~cm}, 130 \mathrm{~cm}$ and $100 \mathrm{~cm}$ respectively. Jayaram [3], Talwar and Jhingran [6] and Tripathi [7] all have reported Sperata seenghala with maximum length of $150 \mathrm{~cm}$ in their collected specimens.

\section{Food and feeding habit}

Sarkar [25] has well documented gross anatomy and histology of the alimentary tract of Sperata seenghala; the anatomical details are as follows: the alimentary tract is comprised of mouth, buccal cavity, pharynx, oesophagus, stomach and intestine. Mouth is a transverse inferior crescentic slit, bordered by lips and jaws; upper jaw projects a little beyond the lower one. The buccal cavity is spacious and dorsoventrally compressed; its roof is slightly arched and the floor is flat. The roof, the floor and the sides are formed of cranium, hyal bones and branchial arches respectively. On the anterior portion of the floor a thick elevated mucosal lining forms the tongue. The teeth (which are homodont and polyphyodont) are arranged in groups in the buccal cavity; they are maxillary, mandibular, vomerine, supra and infra pharyngeal teeth. The vomerine teeth patch is a single crescent patch. Teeth on the jaws are directed inward and are fixed on to the underlying bones by fibrous ligaments. The teeth of supra and infra pharyngeal patches are superficially embedded in the integument. The jaw-teeth are curved and pointed and are largest in the whole set. The pharynx is dorso-ventrally compressed and broad; four pairs of branchial arches are situated on ventro-lateral wall of the pharynx. First and second gill arches bear a single row of 15-16 rakers while the third and fourth carry two rows each with 14-19 rakers. The gill rakers are strong, pointed and antero-dorsally directed. In addition to these, on each side of the pharynx there is row of 14-15 rakers behind the last gill slit. Gill rakers, pharyngeal and other teeth patches help to crush and masticate food items and also prevent to escape of the food material. The pharynx passes into a short, narrow, thick walled oesophagus. The long thick walled stomach is differentiated into cardiac, pyloric and a fundus region. Pyloric stomach opens into coiled intestine which is with three parts- duodenum, intestine and rectum. Duodenum arises from pyloric stomach and runs in close proximity with the sides of the stomach in the upward direction and takes the course of an inverted " $U$ " over the oesophagus. It then continues downward as intestine along the other side of the stomach, makes a simple coil below the fundus and then runs down straight towards the posterior end as rectum. There lies variation in the mucosal surface of different regions of the alimentary tract; buccal mucosa is thick and smooth while pharyngeal mucosal folds are longitudinal and wavy; becomes very prominent at the oesophagus. Height and intensity of folds is higher in fundus region comparative to other regions of the stomach. Duodenum has small web-like folds whose thickness and complexity increase towards the constriction of the duodenum; intestinal folds are complex and fully web-like with different heights while in the rectum they are less intense and wavy with hexagonal or oval folds.

Adult of Sperata seenghala is column feeder [25] and predacious in nature [26,27]; carnivorous feeding habit has been reported by maximum of workers [8-9,11,21,25,28-36], except Agarwal and Tyagi [37], Yeragi and Yeragi [38] and Chacko and Job [39]; Agarwal and Tyagi [37] and Yeragi and Yeragi [38] have reported omnivorous feeding habit while Chacko and Job [39] have documented herbivorous feeding habit for this fish species. Piscivorous feeding habit has been documented by Chacko [28], Alikunhi [21], Karamchandani [40], Menon and Chacko [29], Sarkar [25], Sehgal [11], Bhatt [31], Jayaram [32], Saigal [33], Vinci [34], Anwar and Siddiqui [41], Chondar [8] and
Arif [35] along with presence of considerable amount of insects and insect larvae, prawns, shrimps, crustacean, molluscs, worms and very rarely algae and aquatic weeds in the diet. Chacko and Job [39] have reported algae like Spirogyra, Oscillatoria, Navicula and Pinnularia as the dominant food items in its diet. Bhatt [31] has reported that during guarding the nest, male mainly feeds on debris and do not go out for hunting of fish and other organisms, leaving the larvae unguarded. At fry stage, it mainly feeds on water fleas, insects, fish fry, prawns, copepods and beetle larvae while in fingerling stage its main food items are insects, prawns, copepods, beetle larvae, fish fry and fingerlings of other fish species $[21,40]$. Juveniles are mainly bottom and marginal feeders; predominantly piscivorous, feed mainly on fish fry and fingerlings of other fishes, prawns, shrimps, insects, crustacean, rarely plant matter including debris [33].

Stage wise variation of food preference in Sperata seenghala has been reported by Sehgal [11] and Yadav [42], though Arif [35] has reported no such change in his study. No difference of food preference between juvenile and adult has been reported by Saigal [33].

Seasonal fluctuation in feeding activity in respect to breeding periodicity has been reported by Sehgal [11], Bhatt [31], Vinci [34] and Arif [35], poor feeding intensity has been reported during breeding season while active feeding has been reported after spawning. Saigal [33] has also documented maximum fishes with empty stomach during the breeding season.

Babare et al. [36] have documented increment in amount of animal matter in the diet comparative to plant matter with increase in body size; though Yeragi and Yeragi [38] have reported no such significant change in such amount with body size; they have reported this kind of changes with respect to season and habitat.

Bhatt [31] and Rajagopal [43] have reported cannibalistic nature of Sperata seenghala.

\section{Growth pattern}

Jatoi et al. [44] have reported positive allometric growth for females while isometric growth for male and combined sex of Sperata seenghala in Indus river. Kolekar and Choudhury [23] and Sani et al [45] have reported negative allometric growth for combined sex from Brahmaputra river and Betwa and Gomti rivers respectively.

\section{Sexual dimorphism}

Males of Sperata seenghala can be distinguished externally from the females by the presence of a small stout projection, the urinogenital papilla just above the urino-genital pore which is lacking in females $[28,46]$.

\section{Sex ratio}

Bhatt [31] and Vinci [34] have reported equal proportion of male and female while Jatoi et al. [44] have reported male dominance in their studied samples of Sperata seenghala.

\section{Size and age at maturity}

Bhatt [31] has reported mature specimens of Sperata seenghala with $40 \mathrm{~cm}$ and above $50 \mathrm{~cm}$ in length for male and female respectively. Saigal [33] has observed none of the Gangetic seenghala to be matured below $77 \mathrm{~cm}$ in total length and above $99 \mathrm{~cm} \mathrm{100 \%} \mathrm{maturity} \mathrm{has} \mathrm{been}$ reported. Regarding the age at first maturity few reports are there; Yeragi and Yeragi [38] have reported that this fish species is used to attain maturity at the age of 4-5 months; though Bhatt [31] has reported 
that both the sex mature in their second year of life and Chondar [8] has documented that Sperata seenghala mature in the third or fourth year of their life when size is of $45 \mathrm{~cm}$

\section{Fecundity}

Chacko [28] has reported fecundity of Sperata seenghala to be ranged between 200-1,000; later Bhatt et al. [47] and Saigal [33] have documented fecundity range of 20,064-46,443 and 1,31,820-4,28,376 respectively. High correlation of fecundity with ovary weight and total length in Sperata seenghala has been reported by Saigal [33].

\section{Breeding season}

April to August has been reported as the spawning season for Sperata seenghala in north Indian rivers, Bangladesh and Pakistan and June-July in Punjab [48]. Early May to early June has been reported as the spawning period in Yamuna river at Aligarh [31]. Saigal and Motwani [2] have documented spawning period of seenghala during pre-monsoon and monsoon months (April to August) in river Ganga while Saigal [33] has reported a protracted breeding season of Gangetic seenghala commencing in March and terminating in August with spawning peak in April-May. Seth and Kathia [12] have reported late March to August as the breeding season with April-May as peak breeding months in river Ganga. Sathyanesan [46] has observed breeding season of Sperata seenghala in between March to May in river Ganga at Banaras; Sathyanesan [49] later has documented extension of the breeding period from March to early June at Banaras. Arif [35] has reported July-August as spawning months for seenghala in Gomti river. David et al. [50] have reported its spawning season in between March to May in south Indian rivers; Raj [51] has reported April-May as spawning season in Cauvery river and later also in Bhavani river [26], Chacko and Kurian [52] have reported breeding of seenghala in river Tungabhadra above Sunkesula anicut in between September and December; April-August has been documented as the spawning months in Nagarjunasagar, Andhra Pradesh by Vinci [34]. Kolekar and Choudhury [23] have reported April and October as spawning months in Brahmaputra river, Assam. Alikunhi [21] has reported that Sperata seenghala breeds in rivers as well as in ponds during April to July. Ratanatrivong et al. [24] have reported its spawning season in between January to April in Pai River, Thailand.

Raj [26] has reported synchronization of its breeding periodicity with monsoon floods but Bhatt [31], Talwar and Jhingran [6] and Tripathi [7] have reported that in Sperata seenghala spawning is not at all synchronized with monsoon.

Bhatt [31] and Sugunan [53] have reported Sperata seenghala as a single spawner while Sathyanesan [49], Saigal [33], Kolekar and Choudhury [23], Vinci [34] and Rahman et al. [13,54] have documented it as a multiple spawner.

Migration of Sperata seenghala for breeding purpose from lacustrine environment to riverine conditions has been reported by Ranganathan and Natarajan [55]. Saigal and Motwani [2] while studying early stages of Sperata seenghala from river Yamuna have made similar kind of observation. They have indicated that Sperata seenghala prefer certain environmental condition for its breeding, but no explanation has been given for this. Moderately high water temperatures $\left(22.3-31^{\circ} \mathrm{C}\right)$, sluggish water current and sandy bed have been reported as some of the important factors for breeding of Sperata seenghala in Ganga river $[33,49]$.

\section{Parental care and nest formation}

Phenomenon of parental care in Sperata seenghala has been reported by Raj [26,51], Chacko and Kurian [52], Saigal and Motwani [2], Seth [56] and Seth and Kathia [57].

In natural condition, a sort of nest in the form of circular depression is prepared by the pair of Sperata seenghala at the bottom of the river at shallow water depth by scooping out the earth, among pebbles, amidst rocks, or on the soft muddy beds of rivers or streams for its young ones which are nursed and fed by the male fish for a considerable duration. The breeding pits measure about 0.9-1.2 $\mathrm{m}$ in diameter and $25-45 \mathrm{~cm}$ deep at the centre [51] and at a distance of about $5 \mathrm{~m}$ or more from the water edge [58]. Seth and Kathia [12] have reported that Sperata seenghala used to avoid closed or blind river channel for excavating its nest, primarily for the apprehension that such areas might either get dried in hot summer months causing destruction of the nest or restrict movement of the male parent guarding the nest. Preference of Sperata seenghala for the same nesting sites has also been reported by them. The white secretion (scum) exuding from the inflamed ventral surface of the male parent is eaten by the hatchlings $[2,51]$, this secretion is proteinaceous in nature [51]. Fry after attaining a size of $40-45 \mathrm{~mm}$ has been documented to gradually begin to leave the nest for free life [12].

\section{Fishery}

Sperata seenghala constitutes an important capture fishery of all the major rivers and reservoirs of India, Bangladesh and Pakistan. It constitutes a major component of the fishery in middle and lower stretches of Ganga and Yamuna rivers, ranking next to Hilsa ilisha and Cirrhinus mrigala [8]. Saigal and Motwani [2] have ranked this fish as only next to Hilsa in commercial importance in the Ganga river system. Saigal [33] has reported dominant fishery of this species in Ganga during certain months mainly in late winter and early summer. Kolekar and Choudhury [23] have documented modest fishery of seenghala in Brahmaputra river at Assam.

Seth and Kathia [59] have reported popularity of drag net (locally known as chanta, mahajal and chaundhi), gill net (locally known as ranga, phasla and gochail), purse net (locally known as kamel), hook and line (locally known as jor) and trap (locally known as kuriar and gopal jal) for capturing Sperata seenghala in Ganga river system near Allahabad. The 'chir' fishing which is somewhat similar to gopal jal is a special type of fishing method for Sperata seenghala in Narmada river [60]. Use of gill nets, long lines and sometimes bag nets has been documented by Kolekar and Choudhury [23] in Brahmaputra river for capturing seenghala.

\section{Captive culture and rearing}

Earlier aquaculture potential of Sperata seenghala has not much been explored; complete demand of this fish species in domestic fish markets has been met through capture fishery. Several reasons are there behind the lack of aquaculture of this fish species: brood fishes are difficult to spawn artificially; are sensitive to water quality changes and are easily stressed $[13,54]$. Along with these problems, hatcheries have difficulties in synchronizing the maturity between male and female brood stock, which makes it hard to artificially produce seeds for stocking in grow-out ponds $[54,61]$. Even earlier it was found difficult to rear hatchlings in captivity as no such suitable substitute for scum was there.

Few experimental works have been performed which have shown some silver line for future development of its fishery. Singh et al. [62] have reported successful rearing of seenghala hatchlings by feeding initially with chironomid egg-mass and subsequently with semiboiled trash fish; thus a substitute of scum has been documented by 
them which will pave the way for successful culture of this species. Rahman et al. [54] earlier tried for captive culture of Sperata seenghala but failed; later Khan et al. [63] have achieved a bit of success using Human Chorionic Gonadotropin (HCG) with $80 \%$ fertilization rate; $75 \%$ hatching rate and 56\% survivability. Rahman et al. [64] have conducted an experiment of captive culture of Sperata seenghala involving naturally propagated fry; they have concluded that growth, survivability, production and net benefits of seenghala fingerlings are inversely related to the stocking densities of fry; and stocking density of $1,00,000 \mathrm{fry} / \mathrm{ha}$ has been recommended by them for rearing of seenghala fingerlings for 8 weeks in earthen nursery ponds. Ratanatrivong et al. [24] also tried to culture seenghala in captivity; they have reported $70-90 \%$ survivability of seenghala fingerling while stocked @ 50 fingerlings $/ \mathrm{m}^{2}$ in a $20 \mathrm{~m}^{2}$ concrete ponds and $80-95 \%$ survivability in cage culture with stocking rate of 100 fingerlings $/ \mathrm{m}^{3}$. Polyculture of Sperata seenghala with Indian Major Carps (IMCs) has been tried by Rahman et al. [13] in earthen ponds; they have reported its suitability to be polycultured with major carps with maximum production stocking them in the ratio of 4:3:1.5:1.5 for catla, rohu, mrigal and seenghala. They have concluded that polyculture of seenghala increases the total production of indigenous major carps due to higher growth performances and survival rates; no negative effect of seenghala has been reported by them on major carps in respect to overall growth and production.

\section{Conclusion}

Food and feeding habit of Sperata seenghala has so far been studied by number of workers but except Sarkar [25], none of them have studied it in more details. Maximum of the workers have concluded on food and feeding habit of this fish species just by analysing the gut content of their collected specimens which is a basic technique to ascertain on food and feeding habit of any fish species. Study of morpho-histology of the digestive tract is an effective methodology to conclude properly on food and feeding habit of any fish species and Sarkar [25] has studied the same for Sperata seenghala. Apart from this, enzymatic study of the alimentary canal is also a fine methodology to ascertain on feeding habit of a fish species. So it can be concluded that, though so far, fare information is available on food and feeding habit of Sperata seenghala, more detail study is needed in this aspect. On the other hand, except adult stage, information on food and feeding habit of Sperata seenghala in other life history stages is scanty, just few workers earlier have documented on this aspect; so this should also be studied in details as these information are necessary for proper rearing of fry, juvenile and fingerling stages to get success in captive culture. Scope of research is also there regarding change of feeding habit of this fish species in respect to age, size, sex and habitat if any.

On the other hand, different aspects of reproductive biology of Sperata seenghala has been studied by many workers, but more detail study is needed in all these aspects as most of the information available are full of contradictions. Not much work has been done so far on sex-ratio in natural population of Sperata seenghala; Bhatt [31] and Vinci [34] have reported equal proportion of both sexes while Jatoi et al. [44] have reported male dominance in their studied specimens; so this should be studied properly as information of sex-ratio in natural environment will help out to finalize the ratio of brood stocks to be kept for captive culture. Contradictory information is also available on size at maturity for Sperata seenghala; Bhatt [31] has documented mature specimen of $40 \mathrm{~cm}$ and above $50 \mathrm{~cm}$ for male and female respectively which is close to the report of Chondar [8] while mature specimen with minimum length of $77 \mathrm{~cm}$ has been reported by Saigal
[33]. Contradiction also exists regarding its age at maturity, Yeragi and Yeragi [38] have reported that this species used to mature at the age of 4-5 months while Bhatt [31] and Chondar [8] have documented second and third/fourth year as age at maturity for seenghala. None of the workers have studied length at first maturity (length at which $50 \%$ of the studied samples is at maturity) which is really needed in culture and conservation aspects and to be studied. Information on its fecundity is also scanty and this is also full of contradiction; Chacko [28] has documented low fecundity while Bhatt et al. [47] and Saigal [33] have reported moderate and high fecundity for this fish species. Regarding breeding periodicity little variation has been observed in between north and south Indian rivers; this variation may be due to number of factors like climatic, hydrological, habitat etc though very little work has been done so far on factors affecting breeding of this fish species. Monsoon floods, water temperatures, sluggish water current, sandy bed etc have been documented as factors affecting breeding of seenghala; but firm conclusion is not there and thus detail investigation is really needed to explore much more on this aspect. But most important part to be investigated is its captive culture; information on brood stock rearing and management, suitable artificial breeding methodology, proper rearing technique of larvae, fry, fingerling and juvenile stages to be gathered properly following suitable experiments otherwise it will be really impractical to continue its fishery solely based on capture from nature.

\section{References}

1. Day F (1878) The fishes of India being a natural history of the fishes known to inhabit the seas and fresh waters of India, Burma and Ceylon. William Dowson and Sons, London.

2. Saigal BN, Motwani MP (1961) Studies on the fishery and biology of the commercial catfishes of the Ganga river system. I. Early life history, bionomics and breeding of Mystus (Osteobagrus) seenghala (Sykes). Indian Journal of Fisheries 8: 60-74.

3. Jayaram KC (1977) Aid to identification of siluroid fishes of India, Burma, Sri Lanka, Pakistan and Bangladesh, 1. Bagridae. Records of Zoological Survey of India. Occasional Papers 8: 1-41.

4. Jayaram KC (2002) The fresh water fishes of the Indian region. Narendra Publishing House, New Delhi.

5. Jhingran VG (1991) Fish and fisheries of India (3 $3^{\text {rd }}$ Edition). Hindustan Publishing Corporation, Delhi.

6. Talwar PK, Jhingran AG (1991) Inland fishes of India and adjacent countries.

7. Tripathi SD (1996) Present status of breeding and culture of catfishes in south Asia.

8. Chondar SL (1999) Biology of finfish and shellfish. SCSC Publishers, India pp. 281-293.

9. Rahman AKA (2005) Freshwater fishes of Bangladesh. Zoological Society of Bangladesh, Dhaka, Bangladesh.

10. Saini A, Dua A, Mohindra V (2008) Comparative morphometrics of two populations of giant river catfish (Mystus seenghala) from the Indus river system. Integrative Zoology 3: 219-226.

11. Sehgal P (1967) Food and feeding habits of Mystus seenghala Sykes. Research Bulletin of the Panjab University Science 18: 149-155.

12. Seth RN, Kathia PK (2001) Observations on riverine seed resources of a large catfish Aorichthys seenghala (Sykes). J Inl Fishe Soc Ind 33: 81-86.

13. Rahman MA, Arshad A, Nurul Amin SM (2011) Evaluation of growth and production of the threatened giant river catfish, Sperata seenghala (Sykes) in polyculture with indigenous major carps. Afr J Biotechno 10: 2999-3008.

14. Khawaja DK (1966) Biochemical composition of the muscles of some freshwater fishes during the prematurity phase. Fisheries Technology 3: 94-102.

15. Devadasan K, Varma PRG, Venkataraman R (1978) Studies on frozen storage characteristics of fillets from six species of fresh water fishes. Fisheries 
Citation: Gupta S (2015) Review on Sperata seenghala (Sykes, 1839), A Freshwater Catfish of Indian Subcontinent. J Aquac Res Development 6: 290. doi:10.4172/2155-9546.1000290

Page 5 of 6

Technology 15: 1-6.

16. Mohanty BP, Paria P, Das D, Ganguly S, Mitra P, et al. (2012) Nutrient Profile of Giant River-Catfish Sperata seenghala (Sykes). Nat Acad Sci Lett 35: 155161.

17. Bhuiyan AL (1964) Fishes of Dacca. Asiatic Society of Pakistan, Dacca.

18. Jayalal L, Ramachandran A (2012) Export trend of Indian ornamental fish industry. Agriculture and Biology J North America 3: 439-451.

19. Gupta S, Banerjee S (2014) Indigenous ornamental fish trade of West Bengal Narendra Publishing House, New Delhi.

20. Job TJ, David A, Das KN (1955) Fish and fisheries of the Mahanadi in relation to the Hirakund dam. Indian Journal of Fisheries 2 (1): 1-40.

21. Alikunhi KH (1957) Fish culture in India. Farming Bulletin of Indian Council of Agricultural Research 20: $144 \mathrm{pp}$.

22. Misra KS (1959) An aid to the identification of the common commercial fishes of India and Pakistan. Records of the Indian Museum 57: 156-157.

23. Kolekar V, Choudhury M (1989) Some observation on the biology of Mystus seenghala (Sykes) from the river Brahmaputra in Assam. J Inl Fishe Soc India 21: $47-54$

24. Ratanatrivong W, Anurakchanachai N, Rungpiboonsophit P (2002) Breeding and nursing of Asiatic shovelnose catfish, Aorichthys seenghala (Sykes, 1841).

25. Sarkar HL (1959) Studies on the morpho-histology of the digestive system in relation to the food and feeding habits in a siluroid fish Mystus (Osteobagrus) seenghala (Sykes). Proceedings of the Zoological Society, Calcutta 12: 97-109.

26. Raj BS (1962) The extraordinary breeding habits of the catfish Mystus aor (Ham) and Mystus seenghala (Sykes). Proc Nat Inst Sci India 28: 193-200.

27. Shammi QJ, Bhatnagar S (2002) Applied Fisheries. Agrobios, India.

28. Chacko PI (1955) Observations on the biology and ecology of the inland water fishes of Madras with special reference to their suitability for culture. Fisheries Station Reports and Year Book, Department of Fisheries, Madras.

29. Menon MD, Chacko PI (1958) The food and feeding habits of some freshwater fishes of Madras State. Journal of Bombay Natural History Society 55 (1): 117 124

30. Das SM, Nath S (1965) The comparative anatomy of the alimentary tract and its modifications in relation to food and feeding habits in some fishes of Jammu Province (India). Ichthyologica 4 (1-2): 63-78.

31. Bhatt VS (1970) Studies on the biology of some freshwater fishes. Part V Mystus seenghala (Sykes). J Bom Nat Hist Soc 67: 194-2 1.

32. Jayaram KC (1978) Curious catfishes of India. Zoologiana 1: 9-17.

33. Saigal BN (1982) Biology and fishery of Mystus (Osteobagrus) aor (Hamilton) and Mystus (Osteobagrus) seenghala (Sykes) with a review of the taxonomic status of the genus Mystus scopoli.

34. Vinci GK (1986) Biology of Mystus seenghala (Sykes) from Nagarjuna Sagar Reservoir, Andhra Pradesh. Ind J Ani Sci 56: 814-821.

35. Arif M (2012) Seasonal fluctuations in food and feeding habit in reference to preferential interest in Mystus seenghala (Sykes). J Exp Zoo 15: 97-101.

36. Babare RS, Chavan SP, Kannewad PM (2013) Gut Content Analysis of Wallago attu and Mystus (Sperata) seenghala the common Catfishes from Godavari river system in Maharastra state. Advan Biores 4: 123-128.

37. Agarwal VP, Tyagi AP (1969) Food and feeding habits and the alimentary canal of freshwater fishes of Muzaffarnagar. Agra Univ J Res 18: 15-28.

38. Yeragi SS, Yeragi SG (2014) Food and Feeding habit of Mystus seenghala (Sykes) the common catfish of Mithbav estuary of South Konkan, Sindhudurg District, Maharashtra, India. Inter Res J Sci Eng 2: 71-73.

39. Chacko PI, Job SV (1948) On the nutrition of the young stages of certain fresh water fishes of Madras.

40. Karamchandani SJ (1957) On the occurrence of associates of carp fry in the fry-collection nets and the destructive role played by predatory fish. Ind J Fish 4: 47-61.

41. Anwar S, Siddiqui MS (1992) Observation on the predation by Mystus seenghala (Sykes) and Wallago attu (Bloch and Schneider) of the river Kali in north India. J Environl Biol 13: 47-54.

42. Yadav BN (1997) Fish and Fisheries. Daya Publishing House, Delhi, India

43. Rajagopal KV (1978) Biology of some commercial fishes of the Tungabhadra reservoir with particular reference to utilization of available food, reproduction and growth.

44. Jatoi S, Baloch WA, Soomro AN, Gachal GS (2013) Length-weight relationship of the Silurid catfish Sperata seenghala Sykes 1839 (Bagridae) from Indus River, Sindh, Pakistan. Sindh University Research Journal (Science Series) 45: 661-664.

45. Sani R, Gupta BK, Sarkar UK, Pandey A, Dubey VK, et al. (2010) Lengthweight relationships of 14 Indian freshwater fish species from the Betwa (Yamuna River tributary) and Gomti (Ganga River tributary) rivers. J App Ichthyol 26: 456-459.

46. Sathyanesan AG (1959) Seasonal histological changes in the testes of the cat fish Mystus seenghala (Sykes). J Zoo Soc India 11: 52-59.

47. Bhatt VS, Dalal SG, Abidi SAH (1977) Fecundity of the freshwater catfishes Mystus seenghala (Sykes), Mystus cavasius (Ham.), Wallagonia attu (Bloch) and Heteropneustes fossilis (Bloch) from the plains of northern India. Hydrobiologia 54: 219-224.

48. Khan HM (1934) Habits and habitats of the food fishes of Punjab. J Bom Na His Soc 37: 655-668.

49. Sathyanesan AG (1962) The ovarian cycle in the catfish M. seenghala (Sykes) Proceedings of the National Institute of Sciences, India 28 B (6): 497-506.

50. David A, Rajagopal KV, Gopinathan K (1979) Breeding of fishes, seasonal abundance of young and forage fishes within the Tungabhadra reservoir Proceedings of the National Academy of Sciences, India (B) 49 (4): 183-195.

51. Raj BS (1940) The extraordinary breeding habits of the catfish Aoria (Macrones) aor (Ham. Buch.) and A. (Macrones) seenghala (Sykes).

52. Chacko PI, Kurian GK (1948) A survey of the fisheries of the Tungabhadra river. Proc Ind Acad of Sci 288: 166-176.

53. Sugunan VV (1995) Reservoir fisheries of India. FAO Fisheries Technical paper, Rome.

54. Rahman MA, Uddin KMA, Zaher M (2005) Development of artificial breeding techniques for long whiskered catfish, Sperata aor and giant river catfish Sperata seenghala of Bangladesh. Ban J Fish Res 9: 11-12.

55. Ranganathan V, Natarajan V (1978) Fisheries of Mettur Reservoir, an artificia impoundment on the river Cauvery. Proceedings of the Seminar on the Ecology and Fisheries of Freshwater Reservoirs, CIFRI, Barrackpore.

56. Seth RN (1997) Fisheries, ecology and breeding behaviour of catfish, Aorichthys seenghala (Sykes) with special reference to its management strategies.

57. Seth RN, Kathia PK (2000) Observations on duration of brood care and breeding activities of a large size catfish Aorichthys seenghala (Sykes) in nature. In the fifth Indian Fisheries Forum, Central Institute of Freshwater Aquaculture, Bhubaneswar, India.

58. Singh SP, Malhotra JC, Seth RN, Jain AK (1979) Assessment of seed resources and observations on culture of Mystus seenghala (Sykes) in cages in river Ganga. In: Symposium on Inland Aquaculture organized by Central Inland Fisheries Research Institute, Barrackpore, India.

59. Seth RN, Kathia PK (2003) Riverine fishing methods with special reference to catfishes Aorichthys seenghala (Sykes) and Aorichthys aor (Ham.) Ind J Fisheries 50: 125-130.

60. Karamchandani SJ, Pandit PK (1968) A special fishing method for Mystus (Osteobagrus) seenghala (Sykes) and Mystus (Osteobagrus) aor (Ham.) and certain interesting methods in River Narbada. Journal of Bombay Natural History Society 64: 455-461.

61. Muchlisin ZA, Hashim R, Chong AS (2004) Preliminary study on the cryopreservation of tropical bagrid catfish (Mystus nemurus) spermatozoa; the effect of extender and cryoprotectant on the motility after short-term storage. Theriogenology 62: 25-34.

62. Singh SP, Malhotra JC, Seth RN, Srivastava KP, Chandra K (1981) Observations on rearing of hatchlings of catfish Mystus seenghala (Sykes). Aquacu 26: 161-166.

63. Khan MF, Ali MR, Afzal M, Rab A, Awan MA, et al. (2014) Induced breeding of 
Citation: Gupta S (2015) Review on Sperata seenghala (Sykes, 1839), A Freshwater Catfish of Indian Subcontinent. J Aquac Res Development 6: 290. doi:10.4172/2155-9546.1000290

Page 6 of 6

giant catfish, Sperata seenghala using hormonal analogues. Inter J Veter Sci 3: 125-128.

64. Rahman MA, Arshad A, Yusoff FM, Amin SMN, Marimuthu K, et al. (2014)
Development of captive breeding and seed production techniques for Giant River Catfish Sperata seenghala. Nor Amer J Aquacul 76: 97-103. 